\title{
PERILAKU PADA IKLAN TERHADAP PENGGUNAAN KARTU E-TOLL
}

\author{
Fabianus Fensi \\ Ilmu Komunikasi, Universitas Bunda Mulia \\ Alamat surel: ffensi@gmail.com \\ Michael Christian \\ Manajemen, Universitas Bunda Mulia \\ Alamat surel: michaelchristianid@gmail.com
}

\begin{abstract}
Data shows that some product categories have increased ad spend in 2016. The product categories of government \& political organizations and corporations-public services are increasing 9 to 10 percents. It is expected to achieve the size of the effectiveness of advertising such as sales, reminders or persuasion. The socialization of non-cash payment applications in the form of e-toll cards is a challenge for the government in achieving the realization of use at the end of the year and achieving comprehensive use in the near future. This study aims to explain whether there are behavioral effects on advertising on the use of e-toll cards. This research uses SEM model with SMART PLS 3.0. With an error of 0.5 the results of this study explain that the behavior of e-toll ads impacts a loyalty to the usage and also the impulsive purchase of e-toll cards. The use of socialization strategies with location-based messages (LBMA) is appropriate to reach more users.
\end{abstract}

Keywords: Advertising, Ads, Attitude, e-toll

\begin{abstract}
Abstrak
Data menunjukkan bahwa beberapa kategori produk mengalami peningkatan belanja iklan di tahun 2016. Kategori produk pemerintahan \& organisasi politik dan korporasi-iklan layanan masyarakat diantaranya mengalami kenaikan 9 sampai 10 persen. Peningkatan belanja iklan diharapkan mampu mencapai ukuran efektivitas iklan yaitu penjualan, pengingatan ataupun persuasi. Sosialiasi penerapan pembayaran non tunai dalam bentuk kartu e-toll merupakan tantangan bagi pemerintah dalam mencapai realisasi penggunaan pada akhir tahun dan mencapai penggunaan secara menyeluruh dalam periode dekat. Penelitian ini bertujuan untuk menjelaskan apakah terdapat pengaruh perilaku pada iklan terhadap penggunaan kartu $e$-toll. Penelitian ini menggunakan model SEM dengan SMART PLS 3.0. Dengan galat sebesar 0,5 hasil penelitian ini menjelaskan bahwa perilaku pada iklan e-toll memberikan pengaruh pada loyalitas penggunaan dan juga pembelian kartu e-toll secara impulsif. Penggunaan strategi sosialisasi dengan pesan bebasis lokasi (LBMA) dirasa sesuai untuk menjangkau lebih banyak pengguna.
\end{abstract}

Kata Kunci: Periklanan, Iklan, Perilaku, e-toll

\section{PENDAHULUAN}

\section{Latar Belakang}

Data yang dipublikasi oleh Katadata (Perusahaan Media Online dan Research di bidang Ekonomi dan Bisnis) menunjukkan terjadinya peningkatan belanja iklan di tahun
2016, termasuk belanja untuk iklan yang memiliki kategori produk pemerintahan \& organisasi politik dan korporasi-iklan layanan masyarakat. Untuk kedua kategori produk iklan tersebut mencatat angka pertumbuhan di angka 9-10\% dari tahun sebelumnya (Ardhian , 2017). 
Tabel 1. Pertumbuhan Belanja Iklan Tahun di Indonesia Tahun 2016

\begin{tabular}{lll}
\hline Kategori Produk & $\begin{array}{l}\text { Belanja Iklan } \\
\text { (triliun rupiah) }\end{array}$ & $\begin{array}{l}\text { Pertumbuhan } \\
\text { (dibandingkan tahun } \\
\mathbf{2 0 1 5}\end{array}$ \\
\hline Telekomunikasi & 5,3 & $25 \%$ \\
\hline Situs, layanan daring & 4,4 & $25 \%$ \\
\hline $\begin{array}{l}\text { Korporasi, iklan layanan } \\
\text { masyarakat }\end{array}$ & 3,9 & $10 \%$ \\
\hline Pemerintahan \& organisasi politik & 8,1 & $9 \%$ \\
\hline
\end{tabular}

Sumber: Ardhian (2017)

Anggaran yang telah digunakan untuk belanja iklan tersebut diharapkan memiliki dampak yang terukur bagi perusahaan ataupun organisasi lainnya.Sasaran utama dari suatu iklan adalah untuk menciptakan penjualan (Laudon \& Traver, 2013; Kim \& Han, 2014) menjelaskan bahwa dan membentuk pemerekan (Laudon \& Traver, 2013). Menurut Zoel (2010), efektivitas belanja dalam bentuk iklan dapat diukur melalui pendekatan penjualan (data angka penjualan), pengingatan dan persuasi (dampak komunikasi iklan). Hal ini dapat menjelaskan bahwa tiap iklan yang disampaikan kepada masyarakat memiliki target angka yang ingin dicapai dalam kurun waktu tertentu. Target capaian angka penggunaan kartu electronic toll (e-toll) di gardu tol sudah harus berada pada angka $100 \%$ di tahun 2018 dengan progress menjelang akhir tahun 2016 mencapai 40\% (Destrianita, 2016). Bentuk sosialisasi dalam upaya untuk mencapai angka target tersebut dilakukan pemerintah dengan berbagai strategi, salah satunya dengan media iklan. Iklan mengenai sosialisasi $e$-toll dan hal yang berkaitan dengan e-toll lainnya dapat dilihat di berbagai media elektronik seperti televisi, media daring seperti iklan pada portal/situs, dan media luar ruang seperti billboard yang dapat ditemukan di sepanjang ruas jalan dan pintu gardu tol di Indonesia.
Dampak dari iklan yang ada kepada masyarakat paling tidak dapat membentuk sebagian atau keseluruhan ukuran efektivitas yang ditimbulkan pada iklan seperti yang dijelaskan di atas. Hal ini dapat dapat dimulai dengan membentuk suatu nilai kesadaran yang positif (Lee, Lee, \& Yang, 2017) terhadap adanya informasi mengenai suatu iklan.

\section{TINJAUAN PUSTAKA}

\section{Pengertian dan Keterkaitan Antar Peubah}

Perilaku terhadap iklan dapat dijelaskan sebagai bentuk tanggapan konsumen baik yang bersifat menguntungkan atau pun tidak yang didasarkan dari beberapa faktor pertimbangan yang biasanya melibatkan aspek emosional setelah melihat iklan (Lee, Lee, \& Yang, 2017). Sikap atau perilaku terhadap suatu iklan memiliki pengaruh yang positif dalam menciptakan niat pembelian bagi konsumen (Xu, Oh, \& Teo, 2009). Dalam kaitannya dengan iklan, keinginan pembelian dapat dijelaskan sebagai suatu proses dimana konsumen melakukan rencana untuk membeli produk/jasa sebagai pengaruh dari iklan (Huarng, Yu, \& Huang, 2010).

Impulse buying dapat dijelaskan sebagai suatu kondisi dimana individu secara tiba-tiba melakukan pembelian dengan karakter pembelian yang tidak 
terencana dan keterdesakan untuk membeli yang tidak dapat ditolak (Solomon, 2011). Pesan komunikasi yang terdapat dalam suatu iklan memiliki unsur efek persuasif yang diaharapkan dapat diterima, dimengerti, diinterpretasikan dan dapat berdampak pada tindakan pembelian (Schiffman \& Wisenbelt, 2015). Pengguna yang loyal dapat diidentifikasi dari tingkat keseringan dalam membeli produk/jasa merek tersebut atau komitmen untuk tidak menggunakan merek lain (Schiffman \& Wisenbelt, 2015)

\section{Penelitian Terdahulu}

Sikap atau perilaku terhadap suatu iklan memiliki pengaruh yang positif dalam menciptakan niat pembelian bagi konsumen (Xu, Oh, \& Teo, 2009). Perilaku yang berbeda dapat tercipta dari suatu iklan yang disampaikan kepada masyarakat seperti di USA dan Korea Selatan (Muk \& Chung, 2015). Iklan yang bersifat mobile yang membentuk kesadaran positif bagi masyarakat dapat menciptakan keinginan untuk membeli atau pun menggunakan produk/jasa tertentu (Ha, Park, \& Lee, 2014). Daya tarik promosi melalui media iklan memiliki pengaruh terhadap minat konsumen dalam menggunakan kartu e-toll di kota Semarang (Purnama \& Widyanto, 2012).

\section{Operasional Konstruk \& Hipotesis Penelitian}

Operasional konstruk yang digunakan dalam penelitian ini adalah sebagai berikut:

Tabel 2. Konstruk Penelitian

\begin{tabular}{|c|c|c|}
\hline Peubah & Konstruk & Skala Ukur \\
\hline \multirow{5}{*}{ Advertising Attitude } & Media untuk mengetahui informasi terbaru & \multirow{5}{*}{$\begin{array}{l}\text { Ordinal dengan } \\
\text { likert } 1-5\end{array}$} \\
\hline & Rasa suka pada iklan yang diberikan & \\
\hline & Keinginan untuk menggunakan/membeli lebih banyak lagi & \\
\hline & Memahami pesan iklan & \\
\hline & Performa produk/jasa lebih baik dari iklan & \\
\hline \multirow{4}{*}{ Impulse Buying } & Pembelian yang tidak direncanakan & \multirow{4}{*}{$\begin{array}{l}\text { Ordinal dengan } \\
\text { likert } 1-5\end{array}$} \\
\hline & Kesukaan untuk membeli sesuatu yang tidak direncanakan & \\
\hline & Pembelian secara tiba-tiba menciptakan kesenangan sendiri & \\
\hline & $\begin{array}{l}\text { Menghiraukan konsekuensi ketika melihat sesuatu yang } \\
\text { menarik }\end{array}$ & \\
\hline \multirow{3}{*}{ Loyalty } & Loyal untuk tetap membeli & \multirow{3}{*}{$\begin{array}{l}\text { Ordinal dengan } \\
\text { likert } 1-5\end{array}$} \\
\hline & Merekomendasikan pada orang lain & \\
\hline & Komitmen untuk tidak berpindah ke produk/jasa yang lain & \\
\hline
\end{tabular}

Sumber: Wunas (2012) 
Model dalam penelitian ini mengadopsi model yang pernah dilakukan oleh Wunas(2012) yang terdiri dari peubah bebas (Advertising Attitude), peubah gayut (loyalty) dan impulse buying sebagai pemediasi. Berdasarkan model dan konstruk penelitian yang telah dijelaskan, maka hipotesis yang dibangun pada penelitian ini adalah Loyalty Pengguna Kartu E-toll dipengaruhi oleh Advertising Attitude (H1), Loyalty Pengguna Kartu E-toll dipengaruhi oleh Impulse Buying (H2), Impulse Buying Terhadap Kartu E-toll dipengaruhi oleh Advertising Attitude (H3).

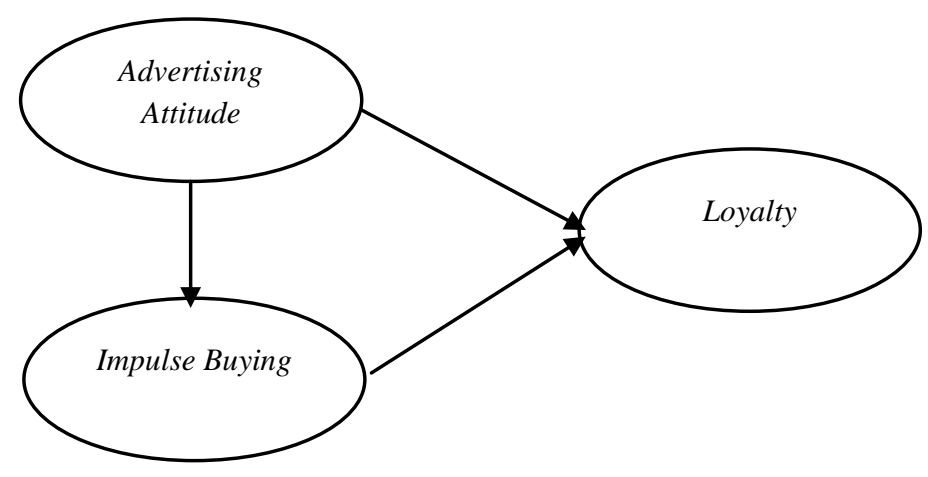

Sumber: data primer

Gambar 1. Model Penelitian

\section{Metode Penelitian}

Penelitian

pendekatan mengugunakan instrumen kuesioner dalam pengumpulan datanya. Jumlah sampel yang digunakan dalam penelitian sebanyak 85 orang dengan dasar indikator dikali dengan 5-10 (Hair, Black, Babin, \& Anderson, 2011). Data akan diolah dengan menggunakan SMART PLS 3.0 dengan angka tingkat kepercayaan sebesar $95 \%$.

\section{HASIL DAN PEMBAHASAN}

\section{Deskripsi Profil Responden Penelitian}

Penelitian ini memiliki karakter responden dengan gender laki-laki sebanyak 45 orang $(52,94 \%)$ dan perempuan sebanyak 40 orang $(47,06 \%)$. Responden dengan usia dengan 18-30 tahun sebanyak 21 orang $(24,71 \%)$, usia $31-40$ tahun sebanyak 18 orang $(21,18 \%)$, usia $41-50$ tahun sebanyak 26 orang $(30,59 \%)$, dan usia di atas 50 tahun sebanyak 20 orang $(23,53 \%)$. Hasil ini menjelaskan bahwa keterwakilan karakter sampel dengan gender laki-laki dan perempuan dapat dikatakan cukup seimbang. Hasil ini juga menjelaskan bahwa jumlah responden berdasarkan usia juga dapat dikatakan merata dengan rentang 21\%-30\%. 
Tabel 3. Deskripsi Profil Respoden, $n=85$

\begin{tabular}{llcc}
\multicolumn{1}{c}{ Deskripsi } & \multicolumn{1}{c}{ Keterangan } & Jumlah & $\%$ \\
\multirow{2}{*}{ Gender } & Laki-laki & 45 & 53,94 \\
\cline { 2 - 4 } & Perempuan & 40 & 47,06 \\
\hline \multirow{2}{*}{ Usia } & $18-30$ tahun & 21 & 24,71 \\
\cline { 2 - 4 } & $31-40$ tahun & 18 & 21,18 \\
\cline { 2 - 4 } & $41-50$ tahun & 26 & 30,59 \\
\cline { 2 - 4 } & & 20 & 23,53
\end{tabular}

Sumber: Hasil Pengolahan

\section{Uji Kesahihan}

Tingkat kesahihan suatu konstruk penelitian dapat dikatakan sahih dengan melihat angka pada model bagian terluar dengan batas 0,70 atau juga bisa berdasarkan angka pada Average Varian Extracted (AVE) dengan batas 0,50 (Ghozali dan Latan, 2015). Butir dalam konstruk yang tidak memenuhi ketentuan akan dikeluarkan (dibuang). Hasil penelitian ini menunjukkan beberapa butir (P3, P5, P6, dan P10) berada di bawah batas ketentuan sehingga harus dikeluarkan. Berdasarkan model bagian terluar setelah diolah maka dapat ditunjukkan bahwa seluruh indikator konstruk dalam penelitian ini dapat dikatakan sahih.

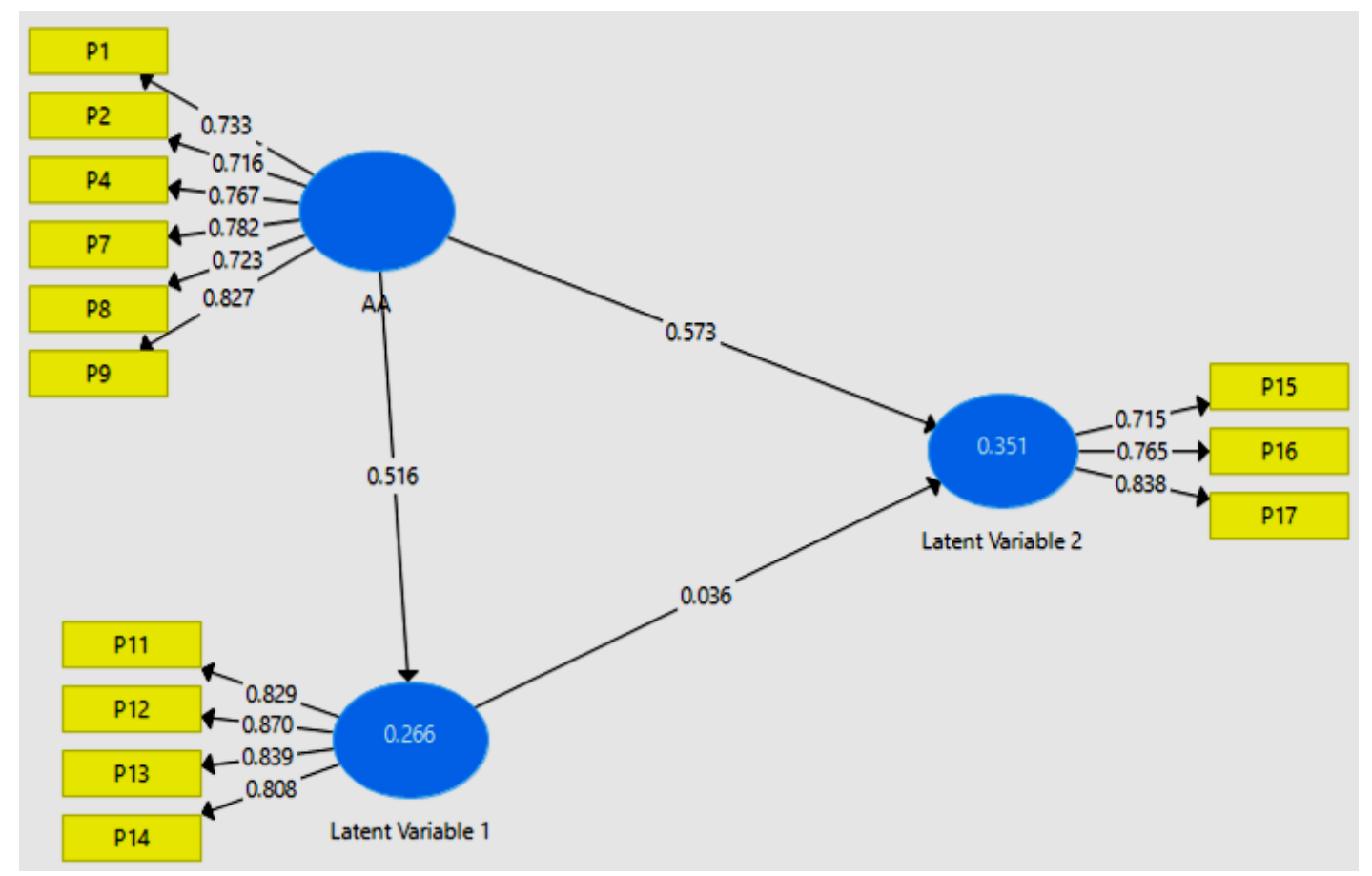

Sumber: data primer yang diolah, $\mathrm{n}=85$

Gambar 2. Model PLS-Algorithm 
Tabel 4. Model Bagian Terluar, $n=85$

\begin{tabular}{lccc} 
& AA & IB & LO \\
\hline P1 & 0,733 & & \\
\hline P2 & 0,716 & & \\
\hline P4 & 0,767 & & \\
\hline P7 & 0,782 & & \\
\hline P8 & 0,723 & 0,829 & 0,838 \\
\hline P9 & 0,827 & 0,870 & 0,715 \\
\hline P11 & & 0,839 & 0,765 \\
\hline P12 & & 0,808 & \\
\hline P13 & & & \\
\hline P14 & & & \\
\hline P15 & & & \\
\hline P16 & & & \\
\hline P17 & & & \\
\hline
\end{tabular}

Sumber: Hasil Pengolahan SMART PLS 3.0

Tabel 5. Average Variance Extracted $(A V E), \mathrm{n}=85$

\begin{tabular}{lc}
\multicolumn{2}{c}{ AVE } \\
\hline AA & 0,576 \\
\hline IB & 0,700 \\
\hline LO & 0,599
\end{tabular}

Sumber: Hasil Pengolahan SMART PLS 3.0

\section{Uji Kehandalan}

Kehandalan dalam suatu penelitian dapat dilihat dari angka Cronbach's Alpha atau Composite Reliability dengan ketentuan di atas 0,70 (Ghozali dan Latan, 2015). Hasil penelitian ini menunjukkan bahwa seluruh konstruk yang ada dinyatakan handal. 
Tabel 6. Compoosite Reliability, $\mathrm{n}=85$

Composite Reliability

\begin{tabular}{ll} 
AA & 0,890 \\
\hline IB & 0,903 \\
\hline LO & 0,817 \\
\hline
\end{tabular}

Sumber: Hasil Pengolahan SMART PLS 3.0

\section{Kesesuaian Model Struktural}

Kesesuian model struktural

dalam penelitian ini dapat dijelaskan dengan melihat pada angka yang terdapat dalam $R$ Square. Hasil penelitian ini menunjukkan bahwa
Advertising Attitude dapat mejelaskan perubahan pada loyalitas sebesar $26,6 \%$ dan impulse buying sebesar $35,1 \%$. Hasil ini menjelaskan bahwa masih terdapat faktor-faktor lain yang dapat memengaruhi peubah gayut.

Tabel 7. $R$-Square, $\mathrm{n}=85$

\begin{tabular}{|c|c|}
\hline & \\
\hline IB & 0,266 \\
\hline LO & 0,351 \\
\hline
\end{tabular}

Sumber: Hasil Pengolahan SMART PLS 3.0

\section{Uji Signifikansi}

Uji signifikansi dapat dijelaskan dari angka $\mathrm{t}$ statistic dalam suatu penelitian. Hasil penelitian ini menunjukkan bahwa angka t-statistic seluruh butir pada penelitian ini berada di atas 1,96 dan dinyatakan memiliki korelasi satu dengan yang lainnya. 
Tabel 8. Model Bagian Terluar, $n=85$

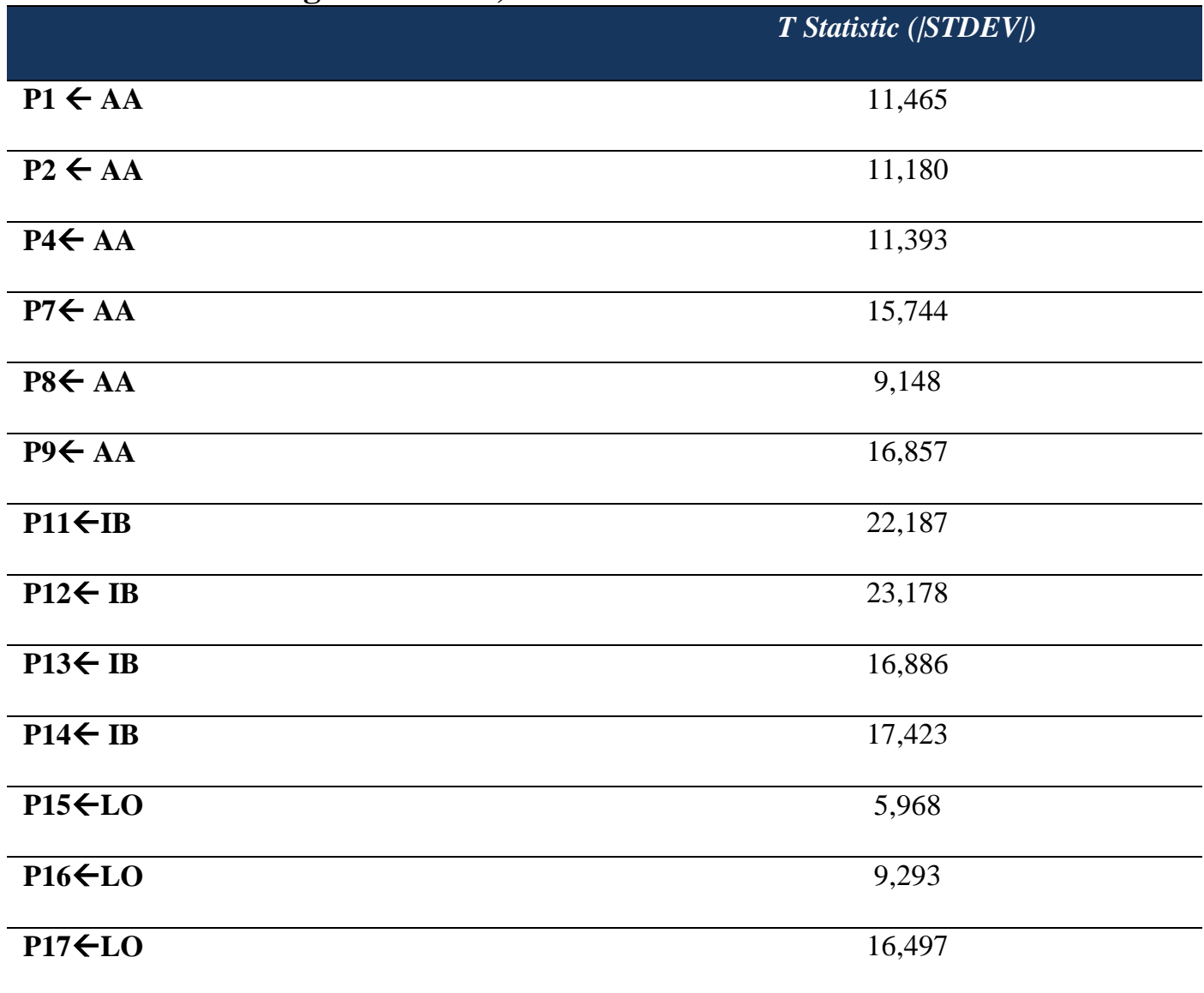

Sumber: Hasil Pengolahan SMART PLS 3.0

Tabel 9. Path Coefficient

\begin{tabular}{lcc} 
& T Statistic $(\mid$ STDEV|) & p values \\
\hline $\mathrm{AA} \rightarrow \mathrm{IB}$ & 6,111 \\
\hline $\mathrm{AA} \rightarrow$ LO & 5,508 \\
\hline $\mathrm{IB} \rightarrow$ LO & 0,296
\end{tabular}

Sumber: Hasil Pengolahan SMART PLS 3.0

Pada bagian path coefficient, hasil penelitian ini menunjukkan bahwa seluruh peubah memiliki pengaruh satu dengan yang lainnya. Advertising Attitude memiliki pengaruh pada Loyalitas (H1) dan terhadap Impulse Buying (H2). Hasil ini juga dapat menjelaskan bahwa Loyalitas pada kartu e-toll dipengaruhi oleh impulse buying
(H3). Secara keseluruhan hasil penelitian ini mendukung hasil penelitian yang pernah dilakukan oleh $\mathrm{Xu}, \mathrm{Oh}, \& \mathrm{Teo}$ (2009); Wunas (2012) dan Ha, Park, \& Lee (2014). 


\section{Simpulan}

Berdasarkan hasil dan pembahasan di atas, maka simpulan penelitian ini adalah sebagai berikut:

1. Perilaku pada Iklan (Advertising Attitude) memiliki pengaruh terhadap loyalitas penggunaan kartu $e$-toll

2. Perilaku pada Iklan (Advertising Attitude) memiliki pengaruh terhadap impulse buying kartu $e$ toll

3. Impulse buying memiliki pengaruh terhadap loyalitas penggunaan kartu $e$-toll

\section{Saran}

Program pembayaran cashless dalam bentuk penerapan pembayaran dengan kartu e-toll dapat dipandang sebagai suatu program yang naik. Namun demikian, keberhasilan program tersebut sebaiknya didukung dengan sosialisasi cara penggunaan dan manfaat yang diperoleh pengguna. Sosialisasi yang ada sekarang dapat dimaksimalisasi dengan bentuk yang lebih tertuju pada dampak secara massal seperti penggunaan strategi pengiriman pesan himbauan dengan metode Location Bases Mobile Advertising (LBMA) seperti yang dilakukan oleh banyak ritel pada suatu pusat perbelanjaan tertentu. Metode ini dapat dilakukan dapat dilakukan di ruas-ruas jalan utama yang ada di Indonesia supaya ketercapaiaan $100 \%$ dalam implementasi program ini dapat semakin didukung oleh berbagai upaya.

\section{DAFTAR PUSTAKA}

Ardhian , M. 2017, Februari Rabu. http://katadata.co.id. Dipetik September Rabu, 2017, dari http://katadata.co.id: http://katadata.co.id/berita/2017/02/ 01/nielsen-belanja-iklan-tembus-rp1348-triliun-berkat-parpol-danpemer

Destrianita. 2016, September Senin. https://m.tempo.co. Dipetik September 13, 2017, dari https://m.tempo.co: https://m.tempo.co/read/news/2016/ 09/12/090803505/jasa-margatargetkan-2018-seluruhpembayaran-pakai-e-toll

Ghozali, I. \& Latan, H. 2015. Partial Least Square: Konsep, Teknik, Dan Apilikasi Menggunakan Program Smartpls 3.0, Semarang, Badan Penerbit Universitas Diponegoro.

Ha, Y. W., Park, M. C., \& Lee, E. 2014. A framework for mobile SNS advertising effectiveness: user perceptions and behaviour perspective. Behaviour and Information Technology, 33(12), 1333-1346.

Hair, J., Black, W., Babin, B., \& Anderson, R. 2011. Multivariate Data Analysis . New Jersey.

Huarng, K. H., Yu, T. H., \& Huang, J. J. 2010. The impacts of instructional video advertising on customer purchasing intentions on the internet. Service Business, 18(4), 446-455.

Kim, Y. J., \& Han, J. 2014. Why smartphone advertising attracts customers: a model of web advertising, flow, and personalization. Computers in Human Behavior, 33, 256-269. 
Laudon, K., \& Traver, C. G. 2013. Ecommerce 2013: Business Technology. Pearson.

Lee, E.-B., Lee, S.-G., \& Yang, C.-G. 2017. The influences of advertisement attitude and brand attitude on purchase intention of smartphone advertising. Industrial Management \& Data Systems, 117(6), 1011-1036.

Muk, A., \& Chung, C. 2015. Applying the technology acceptance model in a two-country study of SMS advertising. Journal of Business Research, 68(1), 1-6.

Purnama, C. A., \& Widyanto, I. 2012. Studi Tentang Minat Beli E-Toll Card di Kota Semarang. Diponegoro Journal of Management, 1(2), 300-310.

Schiffman, L. G., \& Wisenbelt, J. 2015. Consumer Behavior. Essex: Pearson.
Solomon, M. R. 2011. Consumer Behavior. 9 Ed. New Jersey: Pearson.

Wunas , R. P. 2012. Pengaruh Advertising Attitude Terhadap Shopping Loyalty Melalui Impulse Buying Pada Carrefour Golden City Mall mayjen Sungkono Surabaya. Jurnal Ilmiah Mahasiswa Manajemen, 1(1), 1-6.

Xu, H., Oh, L. B., \& Teo, H. H. 2009. Perceived effectiveness of text vs multimedia location-based advertising messaging. International Journal of Mobile Communications, 7(2), 154-177.

Zoel. 2010, May Minggu. http://www.marketing.co.id. Dipetik September 13, 2017, dari http://www.marketing.co.id: http://www.marketing.co.id/evaluasi -efektivitas-iklan/ 